\title{
Differentiation in morphology and flowering phenology between two Campanula thyrsoides $\mathrm{L}$. subspecies
}

\author{
J. F. Scheepens $\cdot$ Patrick Kuss $\cdot$ Jürg Stöcklin
}

Received: 23 September 2010/Revised: 12 January 2011/ Accepted: 17 January 2011/Published online: 9 February 2011

(c) Swiss Botanical Society 2011

\begin{abstract}
Subspecies are usually characterised by sets of morphological discontinuities. By means of common garden experiments, we investigated genetic differentiation in morphological and phenological traits in two geographically disjunct subspecies of Campanula thyrsoides L., i.e. subsp. thyrsoides $\left(=C{ }^{*}\right.$ thyrsoides $)$ occurring in the European Alps and Jura Mountains, and subsp. carniolica $\left(=C .^{*}\right.$ carniolica $)$ occurring in the Southeastern Alps and the Dinaric Arc. Nine out of 16 investigated traits were significantly different between $C$.* thyrsoides and C. $*$ carniolica. For $C$. ${ }^{*}$ carniolica inflorescence length was $1.4 \times$, and above-ground biomass $2.7 \times$ higher, while flower density was significantly lower. Campanula* carniolica also showed delayed flowering and flower development from bottom to top as compared to $C$.* thyrsoides which flowered from top to bottom. The inflorescence growth was indeterminate and flowering took several weeks in $C$. * carniolica, whereas $C$. * thyrsoides showed determinate flowering, rapidly opening all flowers within a few days. This differentiation in flowering phenology is likely to be adaptive. The submediterranean climate favours indeterminate flowering in $C$.* carniolica, allowing ongoing
\end{abstract}

Responsible editor: Christian Parisod.

Electronic supplementary material The online version of this article (doi:10.1007/s00035-011-0087-3) contains supplementary material, which is available to authorized users.

J. F. Scheepens $(\bowtie) \cdot$ J. Stöcklin

Institute of Botany, University of Basel, Schönbeinstrasse 6,

4056 Basel, Switzerland

e-mail: jf.scheepens@unibas.ch

P. Kuss

Institute of Plant Sciences, University of Bern, Altenbergrain 21,

3013 Bern, Switzerland growth of the inflorescence throughout the long summer until environmental conditions worsen, whereas determinate and early flowering in $C$.* thyrsoides is favourable in the short growing season in the high Alps where seed production must be secured before temperature drops. Glacial survival in refugia with different climates (alpine vs. submediterranean) may have caused this regional differentiation.

Keywords Campanula thyrsoides subsp. carniolica . Common garden · Determinate flowering · European Alps . Glacial history

\section{Introduction}

Subspecies are usually characterized by sets of morphological discontinuities but incomplete reproductive isolation (Stuessy 1990). The European Alps are notably rich in endemics, whether at species or subspecies level (Aeschimann et al. 2004), suggesting that speciation rate is high as compared to the surrounding lowland. Glacial history has likely played a major role in taxon differentiation within the European Alpine flora, due to lineage divergence during survival in isolated refugia (Comes and Kadereit 2003; Tribsch and Schönswetter 2003; Paun et al. 2008). Additionally, the spatial heterogeneity of the Alps in terms of topography, geology and regional climate may have caused local or regional adaptation of the various lineages (Alvarez et al. 2009; Stöcklin et al. 2009; Scheepens et al. 2010; Winkler et al. 2010). The last decade experienced a wave of studies investigating differentiation of Alpine species with a focus on glacial history as the driver of neutral genetic differentiation within and among taxa (Schönswetter et al. 2005; Gugerli et al. 2008). While strong genetic barriers 
between intraspecific groups of populations have been widely detected, these molecular studies usually do not extend to differentiation at the phenotypic level and thus may overemphasize the role of neutral processes in differentiation of related taxa (but see Paun et al. 2008; Winkler et al. 2010). In this study on Campanula thyrsoides, we hypothesise the presence of glacial history-related phenotypic differentiation between the subspecies in traits observed in two common gardens and we discuss whether these patterns could be due to adaptation.

Campanula thyrsoides L. (Campanulaceae) is a monocarpic, yellow-flowering bell flower occurring predominantly on calcareous grassland slopes from 1,600 to 2,200 m a.s.l. in the European Alps (Kuss et al. 2007). Seeds have a low dispersal capacity and populations are rare and isolated but sometimes harbour high numbers of individuals, most of them as rosettes and some conspicuously flowering (Kuss et al. 2007). Within-population genetic diversity is high and among-population differentiation is substantial (Kuss et al. 2008a; Ægisdóttir et al. 2009). Its distribution ranges across the European Alps and the Jura Mts. with patchy occurrences in the Dinaric Arc (Kuss et al. 2007), but its occurrence is sparse in the Dolomites and Tyrol. To the west of this distribution gap the subspecies Campanula thyrsoides subsp. thyrsoides $(C . *$ thyrsoides) occurs, and to the southeast of this gap, in the Southeastern Alps and the Dinaric Arc, the majority of populations can be classified to the other subspecies, Campanula thyrsoides subsp. carniolica $(C . *$ carniolica $)$. It is unknown if the two subspecies are interfertile and produce viable offsprings.

The Southeastern Alpine subspecies $C$. * carniolica was first described as a variety by Sündermann (1925) who observed it to be taller than $C$.* thyrsoides due to an elongated inflorescence. Flower density was reported to be more lax in the lower part of the inflorescence as compared to C.* thyrsoides, and its bracts were found to be up to double the length of those of $C$.* thyrsoides. The time of flowering was observed to be delayed for $C$. ${ }^{*}$ carniolica as compared to $C$.* thyrsoides, and Jäger (2000) observed that $C$.* thyrsoides flowered in July and August and $C$.* carniolica in the first half of August, thus partly overlapping in flowering. The varieties were ranked as subspecies by Podlech (1964) based on the marked difference in their geographical distribution in addition to the morphological and phenological characteristics described above: in contrast to the alpine to subalpine $C . *$ thyrsoides, $C$. ${ }^{*}$ carniolica occurs at submontane to montane elevations (400-1,800 m a.s.l.) and is confined to the Carnic area in the broad sense, which includes parts of Italian Carnia and Slovenia (Carnian and Julian Alps) as well as Austrian Carinthia (Jäger 2000; Kuss et al. 2007 and references therein). It has been speculated that these two subspecies are altitudinal vicariants (Tomažič 1941) though the elongated inflorescence of $C$.* carniolica may also be the result of adaptation to the submediterranean climate (Kuss et al. 2007).

Jäger (2000) suggested that the geographic partitioning might be a result of glacial history, the two subspecies having survived glaciated periods in different refugia on the fringes of the Alps. A microsatellite study investigating neutral genetic differentiation among 51 populations of C. thyrsoides across the Alps increased the understanding of the effects of glacial history on intraspecific differentiation (32 Swiss populations in Ægisdóttir et al. 2009; 51 populations in Kuss et al., unpublished results). The amongpopulation genetic structure showed four spatial clusters across the Alps, which corresponded to the general phylogeographic pattern observed in several widespread Alpine species (Schönswetter et al. 2005; Alvarez et al. 2009; ThielEgenter et al. 2009). The most eastern cluster of these belonged to $C$.* carniolica and was clearly separated from the other three to the west, belonging to $C . *$ thyrsoides. Analysis of molecular variance (AMOVA) showed that differentiation between the subspecies $C{ }^{*}$ carniolica and $C$.* thyrsoides (i.e. the single eastern versus the three western clusters taken together) explained $8.4 \%$ of the variation. This was higher than differentiation between clusters within $C$. $^{*}$ thyrsoides and it was even higher than the partitioning of variation among all four distinct groups of populations, i.e. $6.7 \%$. The genetic structure therefore supports the subspecies division of Podlech (1964) and is in line with Jäger's (2000) suggestion that glacial survival in separate refugia is at the origin of the subspecies division.

Morphological differences allow to identify the two subspecies in the field, but a study on their quantitative differences in various traits, however, has never been conducted. Botanists have sometimes found that presumed subspecies phenotypes are merely due to environmental differences, so it is important to be aware of environmental effects on phenotypic expression when taxonomy is concerned (Sultan 2000). To make sure that a quantitative analysis of morphological and phenological differences reflects genetic differences and not the influence of the environment, the subspecies can be grown together in a common garden (Clausen et al. 1948). The uniform environmental conditions in a common garden eliminate variation due to the environmental component, leaving only genetic differences (or rather genotype $x$ environment expressions based on a single environment) between the subspecies to be observed (Connor and Hartl 2004).

In this study, we have chosen traits that are used to differentiate between the subspecies (inflorescence height, number of flowers per inflorescence length, flowering phenology) as well as traits that have not been investigated so far (e.g., leaf size, number of leaves, number of flowers, aboveground biomass). Specific leaf area (SLA) and leaf thickness have been measured because they are known to be 
differentiated between the subspecies (Scheepens et al. 2010). Since $C$.* carniolica generally occurs on roadsides and on rock outcrops, as opposed to $C$.* thyrsoides which mainly occurs in managed grasslands, it is likely that grazing regimes differ between the subspecies, which may have led to adaptive differentiation in response to grazing between the subspecies. Therefore, we assess the response to simulated herbivory in $C$. ${ }^{*}$ thyrsoides and $C$. ${ }^{*}$ carniolica observed in one of the two common garden experiments. Additionally, the common garden results are compared with field data to see if patterns of quantitative differentiation match between the common garden and the field. In summary, we ask (1) whether the subspecies $C$.* thyrsoides and C. * carniolica show glacial history-related differentiation in quantitative traits and (2) whether patterns of differentiation could be explained as adaptation to the subspecies' respective environments.

\section{Methods}

\section{Experimental design}

Two common garden experiments were performed in the Swiss Alps in order to obtain data on 16 quantitative traits. The seed sources of these experiments were populations which have been investigated as part of a phylogeographic study and for which spatial genetic information is available (Ægisdóttir et al. 2009; Kuss et al., unpublished results). The first experiment was located in Davos (1,530 m a.s.l.) and herbivory was simulated by clipping half of the plants 8 weeks after transplantation. This experiment included seed-derived plants from 17 populations of $C$.* thyrsoides and 4 populations of $C$. ${ }^{*}$ carniolica. Six seed families per population and eight individuals per seed family made a total of 963 individuals at the beginning of the experiment (45 individuals were missing from the start).

The second experiment near Chur included three common gardens at different elevations along the slope of $\mathrm{Mt}$ Calanda, Switzerland (600, 1,235, 1,850 m a.s.1.). This experiment included seed-derived plants from 12 populations of $C$. * thyrsoides and 6 populations of $C$. ${ }^{*}$ carniolica. A range of 2-7 (median 7) seed families per population and 2-12 (median 6) individuals per seed family added up to 600 individuals. For both expriments, seeds were germinated in the greenhouse during autumn 2007 and plants were transplanted to the common gardens of Davos and Chur in late spring and early summer 2008, respectively. In total, 15 out of 24 sampled populations were represented in both experiments. Blocks were initially incorporated in both common gardens, but these were never significant and therefore not considered in subsequent analyses. Locations, altitudes and sample size of populations are given in Online Resource 1.
More detailed descriptions of the design of the Chur experiment are given by Scheepens et al. (2010).

Common garden measurements

Eight weeks after transplantation to Davos, survival was recorded and leaf thickness was measured (Teclock SM-112 dial thickness gauge, Okaya, Japan). Number of leaves was counted at the end of the growing season 2008. Length and width of longest leaf were measured at the end of the growing season 2008 as well as at the start of the growing season 2009. Reproductive traits were quantified halfway of the second growing season 2009, i.e. number of inflorescences, total inflorescence length, maximum inflorescence height, total number of flowers on all inflorescences, maximum number of flowers on an inflorescence, and number of flowers per inflorescence length (concerning the flowerbearing part of the inflorescence). Finally, when a plant had finished flowering in 2009, aboveground biomass was harvested, dried for $72 \mathrm{~h}$ at $60^{\circ} \mathrm{C}$, and weighed. Only data from unclipped plants were used (477 individuals), except for data on the response to the herbivory simulation.

Data on SLA and leaf hair density were obtained from the Chur experiment. Details on the measurement of SLA are described in Scheepens et al. (2010). Leaf hair density was measured per individual as the mean number of leaf hairs on five randomly chosen areas of $0.25 \mathrm{~cm}^{2}$ on the topside of leaves. For SLA and leaf hair density, mean values for both subspecies were calculated via population means, which in turn were based on seed family means. For SLA, population averages were calculated for each elevational site, which were subsequently averaged over all three sites. Leaf hair density data were analysed without respect to altitudinal origin.

The response of selected traits to simulated herbivory was expressed as the proportional difference of clipped plants to control plants at the seed family level and averaged at the population level. A value of 1 thereby indicates absence of response in clipped plants relative to the control plants (i.e. full recovery after clipping). The three elevational sites in Chur were used to investigate the response of SLA to the elevation treatment, which was measured as the coefficient of variation at the population level and based on seed family averages.

\section{Field measurements}

The common garden results for inflorescence height, maximum number of flowers per inflorescence as well as number of flowers per inflorescence length were compared with those from field data obtained in 2006 from populations of both $C$.* thyrsoides and $C$. * carniolica in Slovenia, Italy and Austria. Percentage of withered flowers was estimated in 
these natural populations in order to investigate phenological differences between the subspecies. Here, the number of withered flowers was divided by the total number of flowers (including buds).

\section{Data analysis}

Subspecies comparisons were performed for all traits for both common garden and field data using non-parametric Mann-Whitney $U$ tests, which do not rely on normality of the data and are more robust to outliers than Student's $t$ tests (Quinn and Keough 2002). We did not use any correction for multiple testing (e.g., sequential Bonferroni correction; Holm 1979), since most traits showed conspicuous though moderately significant differences between the subspecies, which would be eliminated by a multiple-testing correction (Moran 2003). All comparisons were based on population means, which in turn were based on seed family means for the common garden data. The coefficient of variation was calculated for each trait among populations within each subspecies, in the common garden as well as in the field, to investigate whether the two subspecies differed in variability and whether common garden and field sites differed in variability.

\section{Results}

\section{Common garden measurements}

Nine out of 16 traits were significantly different between C. * thyrsoides and C.* carniolica (Table 1). Post-transplantation survival did not differ significantly between the subspecies. Leaves were on average $10 \%$ thicker and SLA was on average $14 \%$ lower in C.* carniolica. In fact, SLA was lower at all experimental elevations for $C$. * carniolica as compared to $C$. * thyrsoides (data not shown, see Scheepens et al. 2010). Leaf hair density was 53\% higher in C. * carniolica compared to $C$. * thyrsoides, but this difference was not significant. Rosettes of $C$.* carniolica had $25 \%$ fewer leaves. During the following year, flowering C. * carniolica plants had few rosette leaves or none at all, whereas flowering $C$.* thyrsoides plants showed a full (although withering) rosette (J.F. Scheepens, personal observation from both experiments). In both late and early season (i.e. measurements from the first and the second season, respectively), full-grown leaves were remarkably longer and wider in $C$. * carniolica, although width was not significantly different between the subspecies. The number of inflorescences did not differ statistically, but tended to be higher in $C$. * carniolica. The cumulative lengths of inflorescences was 1.8 times higher and the maximum inflorescence length was 1.4 times higher in $C$.* carniolica.
The total number of flowers on all inflorescences as well as the maximum number of flowers on an inflorescence did not differ significantly between the subspecies, but tended to be lower in $C$. ${ }^{*}$ carniolica. The number of flowers per length of inflorescence, however, was significantly lower for C. * carniolica. Finally, above-ground biomass was about 2.7 times higher in $C$. ${ }^{*}$ carniolica.

Variation in trait values was considerably higher in $C$. ${ }^{*}$ carniolica compared to $C$. $*$ thyrsoides $(>5 \%$; Table 1$)$ for the following traits: leaf width at end of season, total number of flowers on all inflorescences and number of flowers per inflorescence length. By contrast, considerably lower variation $(<5 \%)$ was found for leaf hair density, number of inflorescences and aboveground biomass.

Response to simulated herbivory was indifferent between subspecies for most of the selected traits: number of leaves, leaf length and width in both seasons, total inflorescence length and maximum inflorescence height showed comparable variability in the two subspecies (Table 2). Campanula $^{*}$ carniolica showed a significantly larger reduction in number of inflorescences after clipping $(-15 \%$; $P=0.04)$ and a marginally significant larger reduction in aboveground biomass after clipping $(-21 \% ; P=0.07)$. Campanula $^{*}$ carniolica showed a less strong reduction in the number of flowers due to clipping as compared to C.* thyrsoides, but this difference was not significant $(+11 \% ; P=0.26)$. The response of SLA to elevational treatments did not differ between the subspecies (mean \pm se of population-level coefficient of variation (\%): $C$.* thyrsoides $12.4 \pm 1.0 ; \quad C . * \quad$ carniolica $12.3 \pm 1.6$; $P=0.89$ ).

\section{Field measurements}

The field data showed similar differences between the subspecies as did the common garden experiments, but the field and common garden data differed quantitatively (Tables 1, 3). In natural populations, the inflorescence height was 1.7 times higher in $C$.* carniolica as compared to $C$.* thyrsoides. Comparably, in the common garden of Davos the maximum inflorescence height was 1.4 times higher in C.* carniolica (Table 1). Whereas the relative differences were similar between the subspecies, the average heights of 24 and $40 \mathrm{~cm}$ for $C$.* thyrsoides and $C$.* carniolica in the field were smaller than in the common garden, where average heights of 39 and $54 \mathrm{~cm}$ were observed, respectively. The number of flowers did not differ between the two subspecies in the natural populations, in accordance with the results from the common garden. The number of flowers per inflorescence length was $30 \%$ lower in $C$. ${ }^{*}$ carniolica both in the field and the common garden, but the absolute values in the field were smaller than in the common garden. The percentage of withered flowers was only measured in the 
Table 1 Mean, standard error (se), and coefficient of variation (cv) for 16 traits of two subspecies of Campanula thyrsoides L., as well as quantitative differences between subspecies $(\%)$ and significance levels $(P)$ based on Mann-Whitney $U$ tests

\begin{tabular}{|c|c|c|c|c|c|c|c|c|}
\hline & \multicolumn{3}{|c|}{ Campanula* thyrsoides } & \multicolumn{5}{|c|}{ Campanula* carniolica } \\
\hline & Mean & se & $\mathrm{cv}(\%)$ & Mean & se & $\mathrm{cv}(\%)$ & $\%$ & $P$ \\
\hline Survival (proportion) & 0.88 & 0.05 & 22.2 & 0.77 & 0.09 & 22.5 & -12.5 & 0.33 \\
\hline SLA $\left(\mathrm{cm}^{2} \mathrm{~g}^{-1}\right)$ & 160.9 & 2.4 & 5.1 & 137.8 & 3.9 & 6.9 & -14.3 & $<0.001$ \\
\hline Leaf thickness (mm) & 0.486 & 0.006 & 5.1 & 0.534 & 0.021 & 7.9 & 9.9 & $<0.05$ \\
\hline Leaf hair density $\left(\mathrm{cm}^{-2}\right)$ & 15.2 & 3.1 & 70.3 & 23.3 & 4.7 & 49.6 & 53.3 & 0.18 \\
\hline Number of leaves & 131.2 & 6.8 & 21.2 & 97.5 & 10.7 & 22.0 & -25.7 & $<0.05$ \\
\hline Leaf length end of season $(\mathrm{cm})$ & 7.20 & 0.24 & 13.8 & 9.92 & 0.87 & 17.5 & 37.8 & $<0.01$ \\
\hline Leaf width end of season $(\mathrm{cm})$ & 2.65 & 0.08 & 12.5 & 3.31 & 0.37 & 22.6 & 24.9 & 0.08 \\
\hline Leaf length start of season $(\mathrm{cm})$ & 11.3 & 0.4 & 14.6 & 14.1 & 1.0 & 13.9 & 24.8 & $<0.01$ \\
\hline Leaf width start of season $(\mathrm{cm})$ & 1.58 & 0.05 & 12.7 & 1.92 & 0.16 & 16.8 & 21.5 & 0.07 \\
\hline Number of inflorescences & 3.80 & 0.40 & 43.2 & 4.69 & 0.31 & 14.0 & 23.4 & 0.41 \\
\hline Total inflorescence length $(\mathrm{cm})$ & 176 & 14 & 31.7 & 317 & 52 & 32.6 & 80.1 & $<0.05$ \\
\hline Maximum inflorescence height $(\mathrm{cm})$ & 39.2 & 1.3 & 14.0 & 54.3 & 3.8 & 14.2 & 38.5 & $<0.01$ \\
\hline Total number of flowers on all inflorescences & 348 & 25 & 29.8 & 276 & 70 & 50.8 & -20.7 & 0.32 \\
\hline Maximum number of flowers on inflorescence & 102.8 & 4.3 & 17.1 & 86.0 & 9.2 & 21.6 & -16.3 & 0.17 \\
\hline Number of flowers per inflorescence length $\left(\mathrm{cm}^{-1}\right)$ & 6.67 & 0.13 & 8.2 & 4.96 & 0.44 & 17.9 & -25.6 & $<0.001$ \\
\hline Above-ground biomass (g) & 25.7 & 2.5 & 40.4 & 69.5 & 5.0 & 14.4 & 170.4 & $<0.001$ \\
\hline
\end{tabular}

Table 2 Response to simulated herbivory of two subspecies of Campanula thyrsoides L. Given are mean, standard error (se) and coefficient of variation (cv) in ten traits, as well as quantitative differences between subspecies $(\%)$ and significance levels $(P)$ based on Mann-Whitney $U$ tests

\begin{tabular}{|c|c|c|c|c|c|c|c|c|}
\hline & \multicolumn{3}{|c|}{ Campanula* thyrsoides } & \multicolumn{3}{|c|}{ Campanula* carniolica } & \multirow[t]{2}{*}{$\%$} & \multirow[t]{2}{*}{$P$} \\
\hline & Mean & se & $\mathrm{cv}(\%)$ & Mean & se & $\mathrm{cv}(\%)$ & & \\
\hline Number of leaves & 0.82 & 0.02 & 9.7 & 0.83 & 0.03 & 7.8 & 0.78 & 1.00 \\
\hline Leaf length end of season & 0.85 & 0.01 & 6.6 & 0.83 & 0.03 & 7.4 & -3.20 & 0.44 \\
\hline Leaf width end of season & 0.95 & 0.02 & 5.2 & 0.91 & 0.03 & 3.5 & -4.48 & 0.34 \\
\hline Leaf length start of season & 0.84 & 0.01 & 8.7 & 0.81 & 0.01 & 6.9 & -3.70 & 0.18 \\
\hline Leaf width start of season & 0.99 & 0.01 & 5.4 & 0.98 & 0.03 & 5.2 & -1.16 & 0.56 \\
\hline Number of inflorescences & 0.91 & 0.03 & 13.7 & 0.77 & 0.02 & 5.0 & -14.79 & $<0.05$ \\
\hline Total inflorescence length & 0.88 & 0.04 & 18.8 & 0.86 & 0.06 & 14.8 & -2.86 & 1.00 \\
\hline Maximum inflorescence height & 0.99 & 0.02 & 9.5 & 0.95 & 0.04 & 9.5 & -4.05 & 0.75 \\
\hline Total number of flowers & 0.79 & 0.04 & 19.3 & 0.87 & 0.06 & 14.0 & 10.85 & 0.26 \\
\hline Above-ground biomass & 0.84 & 0.07 & 34.2 & 0.66 & 0.02 & 5.4 & -21.10 & 0.07 \\
\hline
\end{tabular}

field and was significantly lower for $C$ * carniolica than for C.* thyrsoides, since populations from the latter finished flowering already at the time of measurement (Table 3).

\section{Phenology}

In the common garden in Davos, $C$. ${ }^{*}$ carniolica showed a delayed flowering as compared to $C$. ${ }^{*}$ thyrsoides. At the start of the second season (1 June 2009) on average $89 \%$ of surviving $C$.* thyrsoides plants had already started bolting, whereas $C$.* carniolica plants showed no signs of bolting yet. On 27 July 2009, 93\% of C.* thyrsoides plants had finished flowering and were in their seed ripening stage and ready to be harvested, whereas $83 \%$ of $C$. $*$ carniolica plants were now fully flowering and $7 \%$ ripening. Harvesting of C. * carniolica took place on 20 October 2009 when snow and frost were abound. However, $C$. * carniolica plants were still flowering or had just started ripening, indicating that they were not adapted to the short growing season at this elevation.

Inflorescences of $C$. ${ }^{*}$ carniolica flowered from the bottom to the top, whereas $C$.* thyrsoides flowered from the top to the bottom. More specifically, flowering in $C$.* carniolica started where the lowest flowers were still closely connected to the inflorescence stem, thus without pronounced secondary stem formation. Below this point secondary stems 
Table 3 Locations and means of four traits in two subspecies of Campanula thyrsoides L. from field data

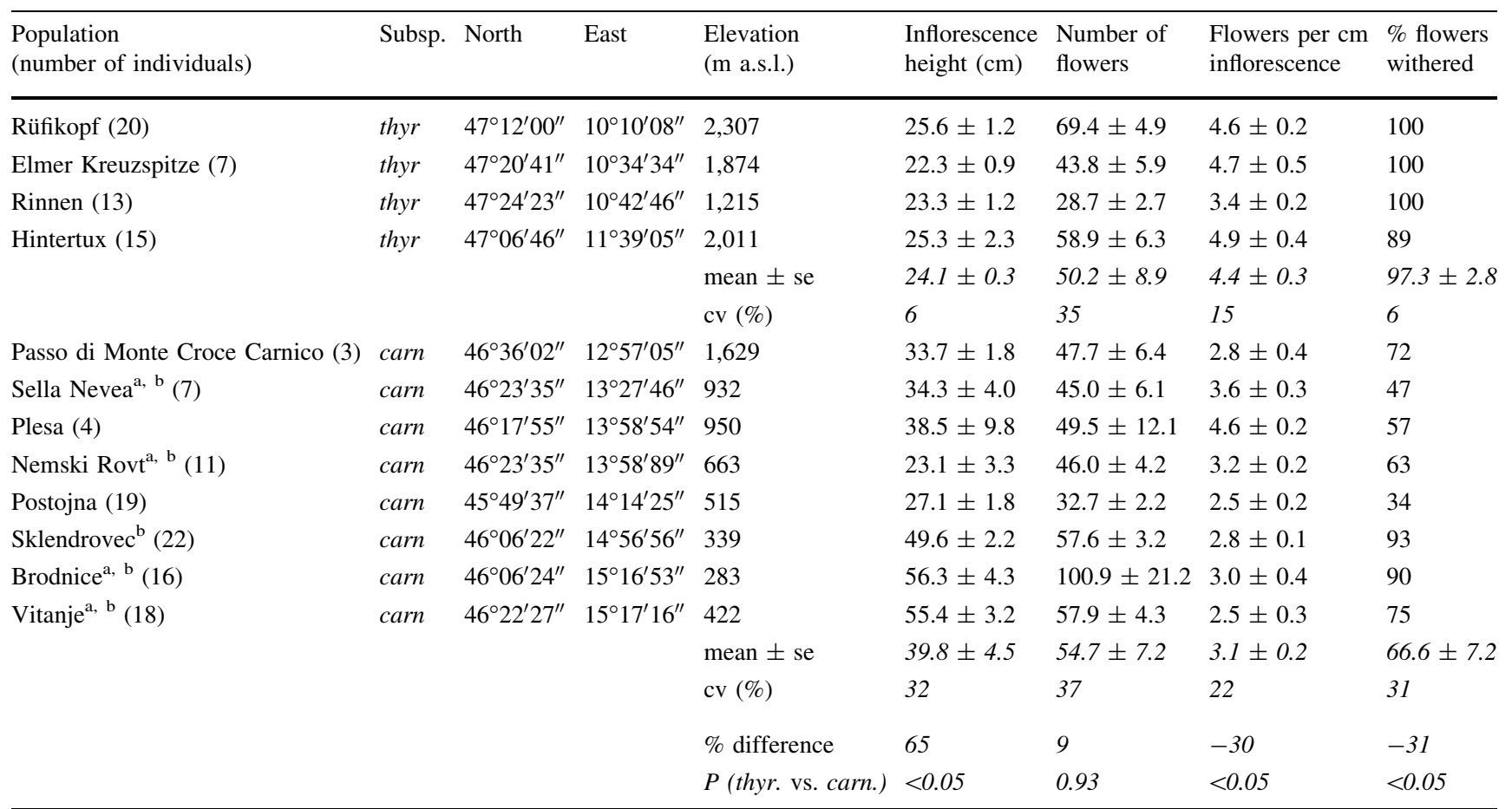

Given are population-level mean \pm se or percentage, subspecies mean \pm se and coefficient of variation (cv), as well as quantitative differences between subspecies $(\%)$ and significance levels $(P)$ based on Mann-Whitney $U$ tests. Subsp. thyr: $C$. thyrsoides subsp. thyrsoides; carn: $C$. thyrsoides subsp. carniolica

${ }^{\mathrm{a}}$ Population also used in the common garden experiment in Davos; ${ }^{\mathrm{b}}$ Population also used in the common garden experiment near Chur (see Scheepens et al. 2010)

usually occured, each with multiple flowers which opened later as well. Flowering was indeterminate in $C$. ${ }^{*}$ carniolica, so new buds were continuously being formed at the apex, and anthesis from bottom to top took several weeks. Consequently, fruits in different stages of ripening could be found below the open flowers. This is in contrast to C. * thyrsoides which showed determinate flowering from the top, rapidly opening all flowers within a few days.

Figure 1 shows the most pronounced differences in the habitus of the two subspecies, including for $C$.* carniolica (i) the taller inflorescence, (ii) the smaller number of rosette leaves in the flowering individual, (iii) the lax flower positioning, (iv) the thinner inflorescence and (v) the indeterminate flowering phenology.

\section{Discussion}

The common garden data support the subspecies division in Campanula thyrsoides since clear differences were observed between the two subspecies in the majority of the examined traits, among them traits used to distinguish the subspecies taxonomically such as inflorescence height (Table 1). Although we did not correct for multiple-testing, obtaining
$P<0.05$ for nine out of 16 traits by chance has a probability of $<1.6 \times 10^{-8}$ based on a Bernoulli process (Moran 2003). The morphological and phenological differences observed in the field were also observed in the common garden indicating genetic differences: $C$. ${ }^{*}$ carniolica showed a taller inflorescence height, a more lax flower positioning and delayed flowering (Tables 1, 3). In addition, the similar number of flowers in the two subspecies was observed in the common garden as well as in the field (Tables 1, 3). Although flower number was similar between subspecies, the advantage of a taller inflorescence in $C$. * carniolica may lie in farther seed dispersal (Tackenberg et al. 2003; Tackenberg and Stöcklin 2008). Lower SLA and higher leaf thickness in $C$. ${ }^{*}$ carniolica have been explained as adaptation to drought in the submediterranean climate (Scheepens et al. 2010). Length and width of leaves showed that start-ofseason leaves were more elongate than end-of-season leaves, which is in accordance with observations by Jäger (2000) who described the two-phased rosette growth of $C$. thyrsoides.

Maternal effects have often been reported to affect a variety of traits, but maternal effects are usually pronounced at the seedling stage while decreasing over time (e.g., Ouborg et al. 1991; Schmid and Dolt 1994). Since plantlets 
Fig. 1 Habitus of Campanula thyrsoides subsp. carniolica and subsp. thyrsoides in three phenological phases of flowering. Scale bars have the same length, indicating the relative size of the two subspecies. Drawing by Atelier Guido Köhler, Basel

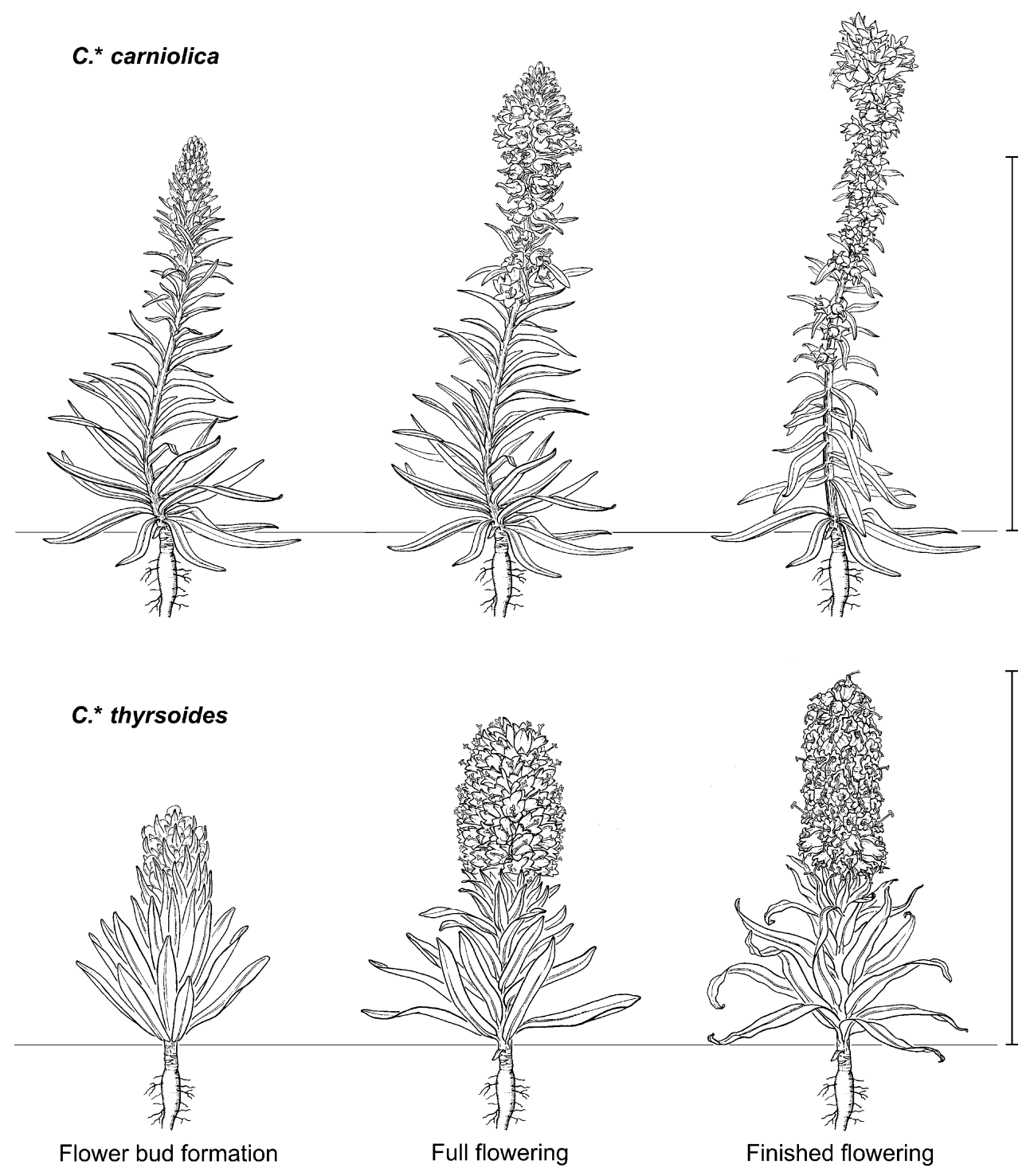

were circa 6 months old at transplantation and since most traits were measured 2.5 months or more after transplantation, we assume that maternal effects are negligible, but cannot verify this. Initial maternal effects can be propagated through unequal intra- and interspecific competition, but a weeded common garden with ample space between experimental plants, as in our study, limits the enhancement of initial phenotypic differences. Genotype $\times$ environment effects were likely to be small in our study, as traits that were measured in both common gardens (comparison not shown) and in the field showed similar patterns.

\section{Common garden versus field measurements}

The common garden and field data showed that observations from experimental and natural settings can diverge. This is most evident from the number of inflorescences: common garden-grown individuals were predominantly multi-stemmed (90\% in Davos, data not shown) in contrast to predominantly single-stemmed individuals under natural field conditions ( $88 \%$, data not shown). It was most likely the benign conditions in the common garden, due to weeding and nutritious soil, which caused the growth of multiple inflorescences. Another notable difference between plants in the common garden and wild individuals is that the latter are reported to flower once after 3-16 years with an average of about 10 years (Kuss et al. 2008b), whereas the vast majority (93\%) of the surviving experimental plants in Davos flowered already in their second year. Comparing the common garden results with the field observations also showed smaller inflorescence height, number of flowers and flowers per inflorescence length in the field. To conclude, on the one hand common gardens are an ideal method to detect and compare genetic differences between subspecies, whereas 
on the other hand the obtained values cannot be used as descriptors to identify the subspecies in the field.

\section{Coefficient of variation}

Knowledge on intraspecific variability in plant traits is important as it could inform us about differences in niche breadth among taxa (Rotundo and Aguiar 2008; Milla et al. 2009; Albert et al. 2010). We found that coefficients of variation were remarkably similar for both subspecies in most traits, notably in those traits that differed significantly in their average values. Exceptions were number of flowers per inflorescence length and aboveground biomass, which differed both in their mean and coefficient of variation. This result indicates that variability in most traits among populations did not differ between the subspecies and may suggest that niche breadths of the two subspecies are similar. This is an interesting result, suggesting that trait variability is inherently constant (relative to the average) whereas average trait values can shift according to environmental conditions.

Another exception to the general pattern was the number of flowers in the common garden, which showed a much higher coefficient of variation for $C$.* carniolica. This high variability could be due to the uncommon environment for this subspecies. The number of flowers at harvesting was probably largely dependent on time of flowering in this indeterminately flowering subspecies, with early flowering individuals yielding more flowers at harvesting than lateflowering individuals, resulting in high variability. In line with this argumentation, the coefficient of variation for the number of flowers of individuals in the field was similar for both subspecies.

Coefficients of variation showed a large range across traits, indicating that some traits (e.g., maximum inflorescence height) were more stable across populations and would therefore be more reliable as taxonomic indicators than others (e.g., biomass). Stronger environmental influences would be expected in the field, leading to increased variability. However, field measurements did not systematically show a higher coefficient of variation than the common garden measurements for the same traits.

\section{Herbivory}

Compensatory growth following herbivory is a general phenomenon in plants, but its extent can differ inter- and intraspecifically (Strauss and Agrawal 1999). This study showed that compensation in $C$. thyrsoides was generally strong and that the response to the herbivory simulation did not differ between the subspecies for most traits (Table 2), suggesting either (a) that any contrasting herbivory pressure between the habitats of the two subspecies did not lead to genetic differentiation in these traits or (b) that the two habitats did not differ in herbivory pressure. Suzuki (2008) similarly found no differences in plasticity in response to clipping in a common garden experiment among three populations of the annual Persicaria longiseta with different long-term deer grazing histories, and Rotundo and Aguiar (2008) likewise observed similar tolerance to defoliation among three populations of Poa ligularis differing in recent sheep grazing histories, although other studies do report differences among varieties or closely related species in response to herbivory simulation (Welter and Steggal 1993; Westberg et al. 2010). It may be that herbivory thresholds, above which plant performance is differentially affected in the subspecies, have not been reached in our experiment (Strauss and Agrawal 1999).

\section{Phenology}

Differences in phenology between the subspecies may be hypothesised based on the contrasting environments they inhabit. As stated in the introduction, Sündermann (1925) reported $C$. * carniolica to flower later than $C$.* thyrsoides,

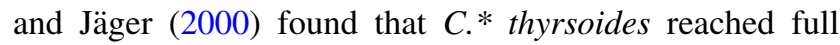
flowering between July and August whereas $C$. ${ }^{*}$ carniolica reached full flowering in the first half of August. In line with these observations, $C . *$ carniolica flowered later than $C . *$ thyrsoides in our common gardens. However, the phenology as recorded from the common garden experiment must not necessarily represent the phenology under natural conditions, since the delayed flowering of $C$. ${ }^{*}$ carniolica may be the result of a genotype $\times$ environment interaction. From the literature it is known that, together with photoperiod and moisture, temperature is a major cue to flowering, usually observed in common garden experiments using plants from different latitudes (Rathcke and Lacey 1985; Weber and Schmid 1998; Olsson and Ågren 2002). If there would be a temperature threshold as cue to flowering in C. * carniolica, this should then have occurred much later in the season at the high elevation of the common garden in Davos. The field observations were in agreement with the observed delayed flowering in the common garden, showing $97 \%$ of flowers of $C$. $*$ thyrsoides plants withered and $67 \%$ of flowers of C.* carniolica withered (Table 3). It should be noted that three of the four $C$.* thyrsoides populations were cencused 1 month later than all other populations in the field study. However, the Hintertux population of $C{ }^{*}$ thyrsoides was measured at the same time as the $C$.* carniolica populations and had also finished flowering ( $89 \%$ withered), thereby contrasting with $C$.* carniolica populations. Thus, the subspecies differ in phenology, with $C$.* carniolica showing delayed flowering. 
Strictly speaking, that $C$.* thyrsoides plants in natural populations were already ripening when $C$.* carniolica was still flowering in Slovenia indicates an earlier end of flowering in $C$ * thyrsoides and not per se advanced flowering initiation. Nevertheless, delayed start of flowering at lower elevation for $C$. ${ }^{*}$ carniolica fits well with the phenology of alpine versus lowland populations, reflecting the different geographical distributions of the two subspecies. Advanced flowering at higher elevations could be explained as adaptation to the short growing season during which the plant needs to fulfill its life-cycle (Kudo 1993; Olsson and Ågren 2002; Sandring et al. 2007). Thus, the delayed flowering of C. * carniolica in Slovenia's relatively low mountains could be explained as adaptation to the submediterranean climate of this area, but more evidence is needed to strengthen this claim. We speculate that this phenological mismatch between the two subspecies as observed in a common environment as well as in the field could essentially entail reproductive isolation, which is a key driver of speciation (Coyne and Orr 2004).

It could be hypothesised that the indeterminate flowering in $C$.* carniolica versus the determinate flowering in C. $*$ thyrsoides is due to adaptation to climate. The submediterranean climate could favour indeterminate flowering in C. ${ }^{*}$ carniolica, because this would allow a longer flowering period throughout the long summer until environmental conditions would deteriorate, whereas determinate and fast flowering would be more favourable in the short growing season in the high Alps where seed production must be secured before temperatures drop.

Our common garden data also showed that $C$. ${ }^{*}$ thyrsoides populations reached full flowering simultaneously. The same was true for $C$. carniolica populations, which flowered simultaneously but later than $C$.*thyrsoides. If it is true that natural populations of $C$.* thyrsoides have a wide range in peak flowering, as is suggested by Jäger's (2000) broad range in flowering time, our data would then suggest a plastic response of flowering to climatic factors, where the common environment in Davos led to synchronous flowering. It could therefore be hypothesised that, although flowering phenology is genetically differentiated between the subspecies, climatic factors influence the timing of flowering within subspecies. This possibility is supported by results from the altitudinal experiment in Chur, where flowering phenology within subspecies was more strongly affected by elevation than by population identity (data not shown). This plasticity in flowering time would be advantageous in the heterogeneous environment of the Alps, enabling dispersed individuals to adapt plastically to their environment. To conclude, phenology is genetically differentiated between subspecies and phenology is phenotypically plastic within $C$.* thyrsoides; both phenomena are potentially adaptive.
Glacial history

Glacial history, besides adaptation to climate, is a likely candidate for allopatric differentiation between the two subspecies (Tribsch and Schönswetter 2003; Schönswetter et al. 2005). Considering the present geographical distributions of the two subspecies, differentiation during glacial survival is even likely to have widened the niche breadth of the species. A general Eastern Alpine refugium southwest of Vienna, either in the most-eastern part of the European Alps or in northwestern Slovenia (both calcareous bedrock), or in the lowland between these two regions (siliceous bedrock), has been proposed based on floristic (Merxmüller 1952, 1953, 1954) and genetic data (Schönswetter et al. 2005). Considering the present-day occurrence of $C$. $^{*}$ carniolica, the region of northwestern Slovenia is a potential in situ refugium where precursors of $C$. $^{*}$ carniolica could have survived. According to the microsatellite data (Kuss et al., unpublished results), at least three other refugia north of the Alps are candidates for the three remaining major phylogeographic groups forming $C$.* thyrsoides. Jäger (2000) explained the differentiation between the two subspecies as the result of isolated glacial survival of $C$.*thyrsoides in one or more colder refugia, to which the subspecies adapted with short, determinate flowering. It thus seems that Jäger (2000) considers $C$. * carniolica to be closer to the ancestral species and $C$.* thyrsoides as the strongly adapted subspecies, deduced from the ancestral species by survival in a highelevation refugium. This proposition is in line with genetic data which shows that the differentiation between the two subspecies is likely older than the differentiation within C.* thyrsoides, which suggests survival in climatically different refugia during the last glacial oscillation (Kuss et al., unpublished results). This glacial survival in contrasting habitats may therefore have resulted in the present allopatric distribution of the two subspecies.

Allopatric subspeciation can result from neutral processes or selection, and both usually go hand in hand (Jolivet and Bernasconi 2007; Schönswetter and Schneeweiss 2009, but see García-Verdugo et al. 2010). Traits that are strongly related to fitness are expected to adapt over time to differences in the environment. We speculate that the allopatric subspeciation of $C$. thyrsoides was initiated by glacial history, as this caused survival in separate refugia and subsequent recolonization of different regions of the Alps, whereas selection processes meanwhile caused differentiation in fitness-related traits between the respective habitats. In this study we reported genetic differentiation in several traits and we argued that some of these traits, such as flowering phenology, were likely due to adaptation to the environment. It is, however, not possible to conclude from our observations to what extent the differentiation is due to adaptation and drift. To discern between neutral genetic drift 
and past selection pressures on the measured traits, $Q_{\mathrm{ST}}-F_{\mathrm{ST}}$ comparisons could be conducted (McKay and Latta 2002).

\section{Conclusion}

The subspecies status of Campanula thyrsoides subsp. thyrsoides and subsp. carniolica is corroborated by the differentiation in morphological and phenological traits observed in the common garden. From an evolutionary point of view, a quantitative description of trait variation is a precondition for an understanding of the evolutionary processes that caused the differentiation and the possible adaptive nature of the differences. The most conspicuous observation in this light is the difference in flowering behaviour between the two subspecies, $C$. $^{*}$ thyrsoides showing determinate and $C$. $^{*}$ carniolica indeterminate flowering. Determinate flowering in $C$.* thyrsoides is likely to be adaptive in the short flowering season in the high Alps, whereas indeterminate flowering may allow $C$.* carniolica to maximise fitness in the long submediterranean summers of Slovenia. This study presented an example where evolution of traits fits with the view that glacial history caused adaptive evolution through long-term survival in contrasting climates in refugia and/or during recolonisation.

Acknowledgments We thank Serge Aubert for helping us collecting plant material in the western Alps, Guy Villaume for practical assistence in the common gardens on Mt. Calanda, Thomas Fabbro and Beatrice Krummen for gathering data from natural populations, Gemeinde Haldenstein and the CCES BioChange project of the ETH Zürich providing access to field sites on Mt. Calanda, and Kai and Christine Huovinen for the experimental site in Davos. This study has been supported financially by the Swiss National Science Foundation, project no. 3100AO-116785 to Jürg Stöcklin.

\section{References}

Ægisdóttir HH, Kuss P, Stöcklin J (2009) Isolated populations of a rare alpine plant show high genetic diversity and considerable population differentiation. Ann Bot 104:1313-1322

Aeschimann D, Lauber K, Moser DM, Theurillat J-P (2004) Flora Alpina. Haupt Verlag, Bern

Albert CH, Thuiller W, Yoccoz NG, Soudant A, Boucher F, Saccone P, Lavorel S (2010) Intraspecific functional variability: extent, structure and sources of variation. J Ecol 98:604-613

Alvarez N, Thiel-Egenter C, Tribsch A, Holderegger R, Manel S, Schönswetter P, Taberlet P, Brodbeck S, Gaudeul M, Gielly L, Kupfer P, Mansion G, Negrini R, Paun O, Pellecchia M, Rioux D, Schupfer F, Van Loo M, Winkler M, Gugerli F, Consortium IntraBioDiv (2009) History or ecology? Substrate type as a major driver of spatial genetic structure in Alpine plants. Ecol Lett 12:632-640

Clausen J, Keck D, Hiesey WM (1948) Experimental studies on the nature of plant species. III. Environmental responses of climatic races of Achillea. Carnegie Institution of Washington Publication, vol 581, pp 1-129
Comes HP, Kadereit JW (2003) Spatial and temporal patterns in the evolution of the flora of the European Alpine System. Taxon 52:451-462

Connor JK, Hartl DL (2004) A primer of ecological genetics. Sinauer, Sunderland

Coyne JA, Orr HA (2004) Speciation. Sinauer, Sunderland

García-Verdugo C, Forrest AD, Balaguer L, Fay MF, Vargas P (2010) Parallel evolution of insular Olea europaea subspecies based on geographical structuring of plastid DNA variation and phenotypic similarity in leaf traits. Bot $\mathrm{J}$ Linn Soc 162:54-63

Gugerli F, Englisch T, Niklfeld H, Tribsch A, Mirek Z, Ronikier M, Zimmermann NE, Holderegger R, Taberlet $\mathrm{P}$, Consortium IntraBioDiv (2008) Relationships among levels of biodiversity and the relevance of intraspecific diversity in conservation-a project synopsis. Perspect Plant Ecol Evol Syst 10:259-281

Holm S (1979) A simple sequentially rejective multiple test procedure. Scand J Stat 6:65-70

Jäger EJ (2000) Wuchsform und Lebensgeschichte der StraußGlockenblume (Campanula thyrsoides L.) und ihrer subsp. carniolica (Sünderm.) Podl. Ber Bayer Bot Ges 69(70):93-100

Jolivet C, Bernasconi G (2007) Molecular and quantitative genetic differentiation in European populations of Silene latifolia (Caryophyllaceae). Ann Bot 100:119-127

Kudo G (1993) Relationship between flowering time and fruit set of the entomophilous alpine shrub, Rhododendron aureum (Ericaceae), inhabiting snow patches. Am J Bot 80:1300-1304

Kuss P, Ægisdóttir HH, Stöcklin J (2007) The biological flora of Central Europe: Campanula thyrsoides L. Perspect Plant Ecol Evol Syst 9:37-51

Kuss P, Pluess AR, Ægisdóttir HH, Stöcklin J (2008a) Spatial isolation and genetic differentiation in naturally fragmented plant populations of the Swiss Alps. J Plant Ecol 1:149-159

Kuss P, Rees M, Ægisdóttir HH, Ellner SP, Stöcklin J (2008b) Evolutionary demography of long-lived monocarpic perennials: a time-lagged integral projection model. J Ecol 96:821-832

McKay JK, Latta RG (2002) Adaptive population divergence: markers, QTL and traits. Trends Ecol Evol 17:285-291

Merxmüller H (1952) Untersuchungen zur Sippengliederung und Arealbildung in den Alpen. I. Jahrb Vereins Schutze Alpenpflanz Tiere 17:96-133

Merxmüller H (1953) Untersuchungen zur Sippengliederung und Arealbildung in den Alpen. II. Jahrb Vereins Schutze Alpenpflanz Tiere 18:138-158

Merxmüller H (1954) Untersuchungen zur Sippengliederung und Arealbildung in den Alpen. III. Jahrb Vereins Schutze Alpenpflanz Tiere 19:97-139

Milla R, Escudero A, Iriondo JM (2009) Inherited variability in multiple traits determines fitness in populations of an annual legume from contrasting latitudinal origins. Ann Bot 103:1279-1289

Moran MD (2003) Arguments for rejecting the sequential Bonferroni in ecological studies. OIKOS 100:403-405

Olsson K, Ågren J (2002) Latitudinal population differentiation in phenology, life history and flower morphology in the perennial herb Lythrum salicaria. J Evol Biol 15:983-996

Ouborg NJ, Van Treuren R, Van Damme JMM (1991) The significance of genetic erosion in the process of extinction. II. Morphological variation and fitness components in populations of varying size of Salvia pratensis L. and Scabiosa columbaria L. Oecologia 86:359-367

Paun O, Schönswetter P, Winkler M, Consortium Intrabiodiv (2008) Historical divergence vs. contemporary gene flow: Evolutionary history of the calcicole Ranunculus alpestris group (Ranunculaceae) in the European Alps and the Carpathians. Mol Ecol $17: 4263-4275$ 
Podlech D (1964) Die Krainer Straußglockenblume. Ber Bayer Bot Ges 37:111

Quinn GP, Keough MJ (2002) Experimental design and data analysis for biologists. Cambridge University Press, Cambridge

Rathcke B, Lacey EP (1985) Phenological patterns of terrestrial plants. Ann Rev Ecol Syst 16:179-214

Rotundo JL, Aguiar MR (2008) Herbivory resistance traits in populations of Poa ligularis subjected to historically different sheep grazing pressure in Patagonia. Plant Ecol 194:121-133

Sandring S, Riihimäki M-A, Savolainen O, Ågren J (2007) Selection on flowering time and floral display in an alpine and a lowland population of Arabidopsis lyrata. J Evol Biol 20:558-567

Scheepens JF, Frei ES, Stöcklin J (2010) Genotypic and environmental variation in specific leaf area in a widespread Alpine plant after transplantation to different altitudes. Oecologia 164:141-150

Schmid B, Dolt C (1994) Effects of maternal and paternal environment and genotype on offspring phenotype in Solidago altissima L. Evolution 48:1525-1549

Schönswetter P, Schneeweiss GM (2009) Androsace komovensis sp. nov., a long mistaken local endemic from the southern Balkan Peninsula with biogeographic links to the Eastern Alps. Taxon 58:544-549

Schönswetter P, Stehlik I, Holderegger R, Tribsch A (2005) Molecular evidence for glacial refugia of mountain plants in the European Alps. Mol Ecol 14:3547-3555

Stöcklin J, Kuss P, Pluess AR (2009) Genetic diversity, phenotypic variation and local adaptation in the alpine landscape: case studies with alpine plant species. Bot Helv 119:125-133

Strauss SY, Agrawal AA (1999) The ecology and evolution of plant tolerance to herbivory. Trends Ecol Evol 14:179-185

Stuessy TF (1990) Plant taxonomy: the systematic evaluation of comparative data. Columbia University Press, New York

Sultan S (2000) Phenotypic plasticity for plant development, function and life history. Trends Plant Sci 5:537-542
Sündermann E (1925) Eine interessante Form von Campanula thyrsoidea L. Allgem Bot Z 26(27):23-24

Suzuki RO (2008) Dwarf morphology of the annual plant Persicaria longiseta as a local adaptation to a grazed habitat, Nara Park, Japan. Plant Spec Biol 23:174-182

Tackenberg O, Stöcklin J (2008) Wind dispersal of alpine plant species: a comparison with lowland species. J Veg Sci 19:109-118

Tackenberg O, Poschlod P, Bonn S (2003) Assessment of wind dispersal potential in plant species. Ecol Monogr 73:191-205

Thiel-Egenter C, Holderegger R, Brodbeck S, Gugerli F (2009) Concordant genetic breaks, identified by combining clustering and tessellation methods, in two co-distributed alpine plant species. Mol Ecol 18:4495-4507

Tomažič G (1941) Senozeti in pasniki na plitvih in suhih tleh Slovenije. Zbornik Prirodoslovnega drustva 2:76-82

Tribsch A, Schönswetter P (2003) Patterns of endemism and comparative phylogeography confirm palaeoenvironmental evidence for Pleistocene refugia in the Eastern Alps. Taxon 52:477-497

Weber E, Schmid B (1998) Latitudinal population differentiation in two species of Solidago Asteraceae) introduced into Europe. Am J Bot 85:1110-1121

Welter SC, Steggal JW (1993) Contrasting the tolerance of wild and domesticated tomatoes to herbivory: agroecological implications. Ecol Appl 3:271-278

Westberg E, Poppendieck HH, Kadereit JW (2010) Ecological differentiation and reproductive isolation of two closely related sympatric species of Oenanthe (Apiaceae). Biol J Linn Soc 101:526-535

Winkler M, Tribsch A, Paun O, Englisch T, Schönswetter P (2010) Pleistocene distribution range shifts were accompanied by breeding system divergence within Hornungia alpina (Brassicaceae) in the Alps. Mol Phylogenet Evol 54:571-582 